\title{
Trayectorias migrantes, movilidad social y recambio étnico nacional en la horticultura (La Plata, Argentina, Siglos XX-XXI)
}

\author{
Migrant trajectors, social mobility and national ethnic replacement in \\ horticulture (La Plata, Argentina, XX-XXI Centuries)
}

\author{
Soledad Lemmi \\ lemmisoledad@gmail.com \\ Universidad Nacional de La Plata. CONICET, \\ Argentina
}

\author{
María Alejandra Waisman \\ alewaisman@gmail.com \\ Universidad Nacional de La Plata. CONICET, \\ Argentina
}

Recepción: 14 Abril 2021

Aprobación: 15 Junio 2021

Publicación: 01 Noviembre 2021

Cita sugerida: Lemmi, S. y Waisman, M.A. (2021).

Trayectorias migrantes, movilidad social y recambio étnico nacional en la horticultura (La Plata, Argentina, Siglos XXXXI). Anuario del Instituto de Historia Argentina, 21(2), e145. https://doi.org/10.24215/2314257Xe145

\begin{abstract}
Resumen: En este artículo nos proponemos reconstruir las trayectorias socio-productivas de horticultores/as del periurbano hortícola de la ciudad de La Plata, capital de la provincia de Buenos Aires, Argentina. Estas trayectorias, condicionadas por procesos macroeconómicos y el devenir de la actividad productiva, explican los recambios en la estructura social hortícola acontecidos en las últimas décadas. En este sentido, la perspectiva de las trayectorias nos ha permitido reunir en el análisis tanto los procesos históricos más amplios y las repercusiones en el espacio local, los condicionamientos estructurales que obstaculizan o facilitan según el caso, como incluir el punto de vista de los/as agentes protagonistas que viven y producen en el periurbano platense. A partir de entrevistas en profundidad y revisión documental pudimos dar cuenta de que las trayectorias están atravesadas por adscripciones étnico-nacionales diferenciales: migración de origen europeo y boliviana, diferentes profundidades temporales y tendencias contrastantes. Sin embargo, más allá de las diferencias, pudimos identificar paralelismos en el proceso de movilidad social ascendente, que implica un mecanismo característico de este sector. Finalmente, abrimos un interrogante sobre el devenir de estas trayectorias, que atraviesan por continuidades y discontinuidades variables.
\end{abstract}

Palabras clave: Trayectorias, Horticultores, Migraciones, Movilidad Social, La Plata.

\begin{abstract}
In this article we propose to reconstruct the socioproductive trajectories of horticulturists in the periurban horticultural city of La Plata, capital of the province of Buenos Aires, Argentina. These trajectories conditioned by macroeconomic processes and the evolution of productive activity, explain the changes in the horticultural social structure that occurred in recent decades. In this sense, the perspective of the trajectories has allowed us to bring together in the analysis, both the broader historical processes and the repercussions in the local space, the structural conditions that hinder or facilitate depending on the case, as well as include the point of view of the main agents who live and produce in the peri-urban area
\end{abstract}




\begin{abstract}
of La Plata. From in-depth interviews and documentary review we were able to realize that the trajectories are traversed by differential ethnic-national ascriptions: migration of European and Bolivian origin; they have different temporal depths and contrasting trends. However, beyond the differences, we were able to identify parallels in the upward social mobility process that imply a characteristic mechanism of this sector. Finally, we open a question about the evolution of these trajectories that go through variable continuities and discontinuities.
\end{abstract}

Keywords: Trajectories, Horticulturists, Migrations, Social Mobility, La Plata.

\title{
INTRODUCCIÓN
}

En este artículo nos proponemos reconstruir las trayectorias socio-productivas de horticultores/as del periurbano hortícola de la ciudad de La Plata (provincia de Buenos Aires, Argentina). Dichas trayectorias están condicionadas por procesos macroeconómicos y el devenir de la actividad productiva; y explican, a su vez, los recambios de las últimas décadas en la estructura social hortícola. En este sentido, la perspectiva de las trayectorias nos ha permitido reunir en el análisis los procesos históricos más amplios y las repercusiones en el espacio local, los condicionamientos estructurales que obstaculizan o facilitan según el caso, e incluir el punto de vista de los/as agentes protagonistas que viven y producen en el periurbano platense.

Este artículo surge de una confluencia de miradas al compartir parte del trabajo de campo en el marco de nuestras investigaciones doctorales, ${ }^{1}$ lo que potenció la discusión (atravesada por lógicas disciplinares particulares) y enriqueció nuestro abordaje sobre el referente empírico en común: el periurbano productivo del partido de La Plata. En el marco de las entrevistas relevamos importantes transformaciones en la estructura social de este espacio acontecidas en los últimos 20 años. Este proceso ha implicado desplazamientos y reposicionamientos al interior del tejido social que, desde lo étnico/nacional, se han reflejado en la categoría de productor/a, que pasó a estar ocupada mayoritariamente por sujetos/as de origen boliviano.

Roberto Benencia fue el investigador pionero en mostrar cómo, hacia 1980 aproximadamente, los/ as migrantes de origen boliviano que habían llegado a la Argentina a trabajar en la producción de hortalizas subían los diferentes peldaños de una escalera de ascenso social, que bautizó como "escalera boliviana" (Benencia, 1999). Cada peldaño implicaba una mejora en su situación en tanto se pasaba de un primer escalón como peón/a a uno segundo como mediero/a y a uno tercero como productor/a. Sin embargo, podemos agregar una nueva variable a esa teorización: la escalera es creada y subida inicialmente por migrantes de origen ultramarino, lo que nos permite considerarla como el mecanismo de movilidad social ascendente característico de la producción de hortalizas del periurbano platense a lo largo de su historia.

Desde el punto de vista teórico-metodológico, partimos de reconstruir las trayectorias socio-productivas de los/as quinteros/as (Gutman, Gutman y Dacal, 1987; Lemmi, 2019). ${ }^{2}$ Consideramos que trayectoria es un concepto mediador que permite reunir en el análisis la historicidad de los procesos sociales, las constricciones estructurales y la agencia de los/as sujetos/as. Si bien este concepto ha sido ampliamente trabajado en las investigaciones sobre inserción ocupacional como trayectorias laborales (Blanco y Pacheco, 2003; Castillo, Novick, Rojo y Yoguel, 2005; Dávolos, 2001; Frassa, 2005; Graffigna, 2005; Muñiz Terra, 2005; entre otros/as); pensamos las trayectorias, junto con Elder (1991, 1994), en el sentido más amplio de cursos de vida, que pueden variar y cambiar en dirección, grado y proporción. Estas trayectorias están siempre inscriptas en contextos espacio-temporales específicos, que implican condicionamientos estructural e históricamente variables. Coincidiendo con Dávolos (2001), concebimos las trayectorias como espacios de 
tomas de decisiones que, aunque socialmente limitados y acotados por instituciones y normas que restringen las opciones de los/as sujetos/as, comprenden siempre un margen de maniobra para hacer frente a los determinantes estructurales. De este modo, se parte de considerar a los/as individuos/as como sujetos/as activos/as, con poder de agencia, que realizan elecciones y toman decisiones, y no como entes pasivos/as sometidos/as exclusivamente a las influencias y limitaciones sociales. No desconocemos, sin embargo, que el ejercicio de la agencia se da en el contexto de una estructura de oportunidades que está moldeada social e históricamente (Bourdieu, 1997). Las trayectorias comprenden una diversidad de dominios de la vida de una persona que interactúan condicionando su curso, entre los que podemos mencionar el trabajo, la vida familiar, la formación y educación, la migración, adscripción étnico-nacional, el género, la edad, etc. Pero debemos entender que muchas decisiones y elecciones que se toman tienen como contexto privilegiado la institución familiar, organización en la que se construye el mundo de vida más inmediato. Por tanto, debemos introducir una advertencia metodológica sobre lo insuficiente que resulta considerar al/la individuo/a como unidad de análisis, ya que es mucho más relevante pensar las trayectorias como familiares. A su vez, el enfoque de las trayectorias implica incorporar la dimensión diacrónica, es decir, la necesidad de tener una perspectiva de largo plazo en la investigación de los procesos sociales, incorporando los factores históricos al análisis. Cabe aclarar, teniendo en cuenta algunos señalamientos críticos de Bourdieu (1997), que no se piensa la trayectoria como un todo coherente y orientado (orden cronológico no igual a orden lógico), sino como una rapsodia compuesta de elementos yuxtapuestos sin razón intrínseca, contingente y discontinua (Waisman, 2011a).

En este sentido, teniendo en cuenta el "margen de maniobra" que los/as sujetos/as con quienes interactuamos para este trabajo han desplegado para hacer frente a los condicionantes estructurales, se ha puesto especial atención en los conflictos que han enfrentado. La preocupación por la acción colectiva y la lucha de estos/as actores y actrices en coyunturas desfavorables de la actividad forman parte de nuestras decisiones teórico-metodológicas, en tanto se vislumbra allí un lugar privilegiado para observar la agencia de los/as sujetos/as, que hacen frente a los condicionantes del sistema capitalista en su tendencia constante a la concentración y centralización (Lemmi, 2015a, 2015b).

De este modo, en el devenir de procesos que han afectado a la estructura social hortícola platense segmentación étnico/nacional de la estructura hortícola entre mediados de 1990 y comienzos del siglo XXI-, identificamos dos tendencias en las trayectorias socioproductivas, que se presentan como contrapuestas pero íntimamente vinculadas: unas, caracterizadas por el abandono de la producción directa pero manteniendo la propiedad de la tierra; otras, trayectorias definidas por la movilidad social ascendente, que reposicionan a los/as migrantes bolivianos/as a la categoría de productor/a a partir de su previa inserción como medieros/as, a través del arriendo de tierras cedidas por los/as primeros/as. Por otra parte, los cambios en la configuración del tejido social deben ser analizados, a su vez, como correlato de otras transformaciones que han afectado a la actividad económica principal, es decir, la producción hortícola, que ha atravesado por un proceso de intensificación asociado a la expansión del paquete tecnológico del invernáculo (García, 2011).

Más allá de que la herramienta conceptual de las trayectorias socio-productivas nos permitió explicar las reconfiguraciones en la estructura hortícola, el debate sobre el devenir de estas trayectorias se prolonga durante el siglo XXI; especialmente, con el cambio de orientación en materia de política pública y medidas macroeconómicas, desde la asunción de la Alianza Cambiemos (PRO-UCR) en la administración gubernamental a nivel nacional, provincial y local en diciembre de 2015. En este contexto, las trayectorias atraviesan continuidades y discontinuidades variables, debido a factores económico-productivos como también a consecuencia de variables intrafamiliares: la capacidad productiva de la fuerza de trabajo involucrada en función de su edad y ocupaciones "extra quinta"; los anhelos de ascenso social -de la mano de su condición de migrantes-; y la posibilidad de acceso a los diferentes medios de producción (básicamente, tierra y capital) según cada generación. En este sentido, la permanencia o expulsión de la producción, así como la diferente posición alcanzada en la escalera de ascenso social, dependen de la historia particular de cada una de estas familias y de las decisiones que han ido tomando, en el marco de opciones estructuralmente 
acotadas. Nos proponemos presentarles aquí una historia de la producción de hortalizas en la ciudad de La Plata, historia que depende, acompaña y sólo pudo ser construida a partir del análisis de las trayectorias recorridas por las familias migrantes de origen europeo y latinoamericano.

Para ello se realizaron entrevistas semiestructuradas a familias vinculadas en la producción (tanto de origen europeo como latinoamericano), que recorren con sus relatos su propia historia familiar junto a su historia productiva. Las decisiones que los/as llevan a migrar a la Argentina, las variables que analizan para insertarse en la producción de hortalizas y su particular historia de vida se ven retratadas en ellas. La información presentada aquí fue recabada mediante trabajo de campo desarrollado durante un período que abarca los años 2009-2019. Esta información se referencia en este trabajo como "Fuente: Acervo testimonial".

Este artículo se estructura en cuatro apartados. En el primero de ellos abordamos las trayectorias de quienes fueron los/as primeros/as migrantes en dedicarse a la horticultura en la región. En segundo lugar, recomponemos los años de la crisis que llevó a encauzar estas trayectorias en situaciones de conflictos y reconfiguraciones. En el tercer apartado, presentamos las trayectorias que llevaron al recambio étnico/ nacional en la región bajo estudio. Finalmente, planteamos los nuevos desafíos que se presentan a estas trayectorias familiares en la continuidad intergeneracional del oficio.

Por último, planteamos algunas reflexiones que, lejos de poder cristalizar en conclusiones finales, nos abren nuevos interrogantes para seguir explorando las trayectorias de los/as sujetos/as con quienes interactuamos para este trabajo en un contexto en permanente cambio como es el sector hortícola platense.

\section{Trayectorias migrantes Ultramarinas: FUndando LA EScalera "Gringa" De ASCENSO SOCIAL}

Tanto en sus orígenes como en la actualidad, el tejido social que conforma el territorio periurbano hortícola platense se ha configurado a partir de trayectorias migrantes. La ciudad de La Plata fue fundada en 1882 para reemplazar la capital de la provincia de Buenos Aires al pasar la ciudad homónima a depender de las autoridades nacionales. El cinturón hortícola de la nueva ciudad surgió también en 1882 para abastecer a su población de alimentos frescos. Al momento de planificar la urbe se proyectó un sector de quintas que bordearían el perímetro urbano, así que la producción de hortalizas estuvo presente en la ciudad desde sus inicios, o incluso antes, cuando sólo era un proyecto en la mente de sus creadores (Ringuelet, 2000; Garat, Selis y Velarde, 1999; García y Lemmi, 2011).

Los/as migrantes que se dedicaron específicamente a la horticultura arribaron a la ciudad en el período de entreguerras: escapaban tanto de la situación bélica como de los problemas económicos que acuciaban a las clases campesina y trabajadora en Europa. De esta manera, prevaleció la radicación en la región platense de sujetos/as pauperizados/as provenientes en su gran mayoría de Italia, aunque también españoles/as y portugueses/as, con saberes acumulados en el trabajo de la tierra y que vinieron a instalarse directamente en las quintas, convocados/as por algún familiar o paisano/a de su lugar de origen. La primera forma de relación contractual fue individual y bajo la modalidad de peones/as asalariados/as (en general, los/as adultos/as cabezas de familia en un primer momento). Más adelante, se pasó a percibir el pago del trabajo como porcentaje de lo producido, es decir a destajo; podía estar incluida toda la familia en el trabajo, para incrementar la producción y “abaratar” costos (Ringuelet, 2000; Lemmi, 2015a, 2015b).

En un período que abarca poco más de 30 años, desde mediados de los años 30 a fines de los 60 aproximadamente, los/as migrantes europeos/as pasaron de ser peones/as a medieros/as, para luego llegar a ser productores/as, bajo la figura de arrendatarios/as o de propietarios/as, con lo que aportaban cada vez menos trabajo físico en la quinta. La existencia de tierra disponible, las posibilidades de trabajar el núcleo familiar completo, los bajos costos de los medios de producción, los precios de las hortalizas elevados y la baja competencia permitieron obtener mayores ganancias y por lo tanto un mayor poder de ahorro e inversión en compra de tierras, en un contexto socio-histórico de políticas estatales facilitadoras. Paralelamente, la 
ampliación familiar y la generación de nuevos matrimonios, en muchos casos con miembros/as de otras familias de la zona que también eran productores/as de hortalizas, reforzaban la presencia de esta comunidad en la actividad y la región. ${ }^{3}$

El trabajo en la horticultura fue en este período la principal fuente de ingresos para esta corriente migratoria, que con tal fin ocupó la totalidad de la mano de obra familiar. A la hora de sumar trabajadores/ as no familiares, la forma históricamente predominante en la horticultura ha sido la denominada "mediería", forma de pago por productividad que, al trasladar hacia los/as trabajadores/as parte de los riesgos de la actividad, permitió obtener márgenes de ganancia que favorecieron la movilidad social ascendente de los/as productores/as. ${ }^{4}$

Las condiciones de vida en los inicios resultaron muy austeras: viviendas sencillas que fueron mejorando en la medida que se daba el proceso de ascenso social, y llegaron a tener agua potable y luz, aunque no siempre gas natural, y con permanente restricción del consumo en función de favorecer el ahorro. Las condiciones de trabajo fueron muy duras ya que implicaban largas jornadas de labor al rayo del sol en pleno verano o bajo la lluvia en invierno. Tanto los/as productores/as como los/as trabajadores/as han sido asiduos/as demandantes de los servicios públicos de salud y educación, lo que les permitió sobrevivir de una mejor manera sin que esto implicase grandes erogaciones de dinero 5 (Ringuelet, 2000). Los sacrificios a que estas familias se sometieron también forman parte de las características que poseen los diferentes peldaños que componen la escalera de ascenso social. Ellos/as fueron los/as primeros/as en construirla y subirla; los/as seguirán más adelante otros/ as migrantes.

Hacia 1960 comenzaron a afluir a las quintas locales trabajadores/as provenientes de las provincias del norte del país, principalmente santiagueños/as, seguidos/as por salteños/as y jujeños/as, que comenzaron, como los/as otrora migrantes europeos/as, como peones/as y medieros/as. Posteriormente, a partir de la década de 1970, comenzaron a arribar migrantes de origen boliviano, que serán paulatinamente "preferidos/ as" para ocupar estas posiciones.

\section{CRISIS, CONFLICTOS Y RECONFIGURACIONES}

Hacia fines de los años 80 y comienzos de los 90 el tejido social del periurbano productivo estaba conformado por la segunda y la tercera generación de hijos/as ya criollos/as de inmigrantes ultramarinos/as, en su rol de productores/as (propietarios/as o arrendatarios/as, patrones/as y directores/as de la producción), como también hegemónicos/as en los procesos de comercialización. Algunos/as de ellos/as habían logrado ascender socialmente y ya no aportaban trabajo físico en la quinta, y cumplían sólo una función gerencial. Nacieron en ellos/as nuevas expectativas de consumo, como demandas de mejor calidad educativa y más tiempo de ocio y vacaciones. Pudieron, además, prescindir del trabajo de sus hijas e hijos en la producción, con lo que marcaron una distancia con su propia socialización en tanto ellos/as sí acompañaron desde niños/as el trabajo en la quinta. ${ }^{6}$

A su vez, como parte del entramado social, los/as migrantes latinoamericanos/as e internos/as aportaron casi en su totalidad la fuerza de trabajo como peones/as y medieros/as, trabajando toda la familia para poder hacer una diferencia y obtener márgenes de ahorro, restringiendo para lograrlo, al igual que los/as inmigrantes ultramarinos/as en sus orígenes, los gastos personales. Si bien los/as inmigrantes bolivianos/as arriban a la zona desde fines de los 70, durante los 90 fueron tornándose mayoritarios/as por dos razones: eran preferidos/as por ser "buenos/as trabajadores/as" (en ocasiones se iba a buscarlos directamente a Bolivia) y por la situación coyuntural de ambos países: un país de origen sumamente pauperizado y un país receptor con una paridad cambiaria (Convertibilidad) que favorecía el envío de remesas (Ringuelet, Attademo, Archenti y Salva, 1991; Benencia, Quaranta y Souza Casadinho, 2009). 
Sin embargo, estas trayectorias no se comprenden si no se retoman algunos procesos que sucedieron durante mediados de la década del 80 y que se continuaron a lo largo de la década del 90, que tendrán consecuencias sobre la conformación futura del tejido social hortícola. Los/as productores/as descendientes de los/as migrantes ultramarinos/as fueron los/as encargados/as de invertir y gestionar nuevas tecnologías en la producción hortícola. Consolidada la producción en el periurbano platense, ésta adquirió una nueva dinámica ya que comenzaron a impulsarse profundas transformaciones tecnológicas: mecanización, agroquímicos, híbridos, riego localizado, fertirrigación y la incorporación del invernadero, que tuvieron grandes repercusiones en los rendimientos, la calidad de la producción, la demanda de insumos, la comercialización y la utilización y remuneración de los distintos factores de producción (Hang, Bifaretti y Sarandón, 1995; Vega, 1999; García y Hang, 2007; García, 2011).

Las nuevas condiciones que exigía la producción, tanto en capital para la inversión de tecnologías como en las nuevas lógicas de comercialización, llevaron a que un sector importante de productores/as criollos/ as no pudieran afrontarlas desde sus escalas de producción y sus niveles de acumulación. Así, a pesar de poseer la propiedad, terminaron endeudados/as con organismos de crédito, sin poder renovar los medios de producción, o no pudieron hacer frente a los acreedores. Los años que van desde 1994 -aproximadamentehasta el 2002 estuvieron atravesados por una profunda crisis estructural para los/as productores/as y los/ as trabajadores/as. Surgió una clara diferenciación hacia arriba y hacia abajo entre los/as productores/as en lo referente a capitalización y productividad, lo cual trajo aparejado un aumento en la confrontación, con acciones que poseyeron una visibilidad notable y con un alto grado de violencia para los parámetros de lucha habituales en el sector. A través de diferentes métodos como asambleas, declaraciones, movilizaciones y cortes de calles, los/as sujetos/as involucrados/as mediante las asociaciones de productores/as en las que participaban, intentaron incidir en la forma en que las políticas del Estado municipal, provincial y nacional afectaban al sector; otros/as denunciando la situación de precarización laboral en que se encontraban (Lemmi y Waisman, 2013; Lemmi, 2015a, 2015b).

La mayoría de estas acciones fueron motorizadas por la Asociación de Productores Hortícolas de La Plata (APHLP) y la Asociación de Medieros y Afines (ASOMA) (vigentes desde los años 80); mientras que a partir de 1998 apareció en escena, también de manera destacada, la Asociación de Quinteros de La Plata (AQLP). Estas tres organizaciones fueron las más visibles y activas en la representación de productores y peones medieros en la región platense. La APHLP y la AQLP estaban compuestas mayoritariamente por familias productoras cuyos/as miembros/as descendían de los/as migrantes europeos/as. No así la ASOMA, que se encontraba conformada por familias migrantes bolivianas. Por otro lado, los/as productores/as más capitalizados/as se agrupaban en la APHLP, y algunos/as medianos/as, pero sobre todo los/as chicos/as, en la AQLP; y las familias en situación de mediería o productores/as familiares muy pequeños/as, en la ASOMA.

La más numerosa y políticamente influyente fue la APHLP que, como parte de sus actividades asociativas, organizaba viajes para visitar países con producciones hortícolas al tamente tecnologizadas; propiciaba la visita y asesoramiento de técnicos y laboratorios que producían semillas y químicos destinados a la horticultura; y anualmente organizaba la Fiesta Provincial de la Horticultura/Expo Hortícola, que al ir creciendo año a año se convirtió en la "Semana de la Horticultura". Esta organización estuvo conformada mayoritariamente por varones, si bien las mujeres productoras propiciaban activamente la participación de los hombres en ella. Las preocupaciones de la producción eran compartidas por el conjunto de la familia hortícola, aunque las mujeres no tuvieran un papel visible en la dirección de la asociación, ni se plantearan actividades específicas para los/ as jóvenes. Las mujeres participaban activamente de las tareas productivas, y de las festivas y exposiciones en el marco de la asociación. Trabajaban largas horas en la preparación de las comidas, los salones y las actividades de sostenimiento de la Expo. Sin embargo, el lugar de visibilidad pública fue guardado para los varones productores. ${ }^{7}$

Este no fue el caso de la ASOMA, organización con un fuerte componente de mujeres que desempeñaban un rol central en las diferentes instancias de la asociación. Ellas participaban, en tanto campesinas, en el 
Encuentro Nacional de Mujeres que se organizaba todos los años. Allí planteaban sus reivindicaciones sectoriales y confluían con otras compañeras del sector rural de la Argentina y Latinoamérica. De hecho, una mujer formó parte durante doce años de la Comisión Directiva de la asociación. Asimismo, destacaron el rol relevante de la juventud horticultora y la necesidad de políticas destinadas a estos/as jóvenes en particular (Lemmi, 2009).

Luego de haber realizado una importante inversión de capital, aumentado la productividad en el sector y modificado el proceso de trabajo, acorde todo con el discurso productivista reinante, las familias productoras se encontraron con un mercado sobreofertado y al mismo tiempo subdemandante producto de la crisis económica, en el cual la verdura se vendía por debajo de su valor, lo que ocasionaba grandes pérdidas. Se le sumó que las nuevas tecnologías, especialmente el invernáculo y la mayor inversión inicial que requería su construcción (madera, nylon, mano de obra), implicaron que, frente a una tormenta fuerte, con vientos y caída de granizo, los invernaderos debieran volver a construirse, lo que generaba una nueva inversión; además, en muchas ocasiones, también se perdían los cultivos (Lemmi, 2015b).

Una vez que habían subido todos los peldaños de la escalera, los/as descendientes de italianos/as y españoles/as no cedieron a la exigencia de retracción del consumo o al descenso en su nivel de vida, como lo habían hecho sus abuelos/as y padres y madres, y lo hacían los/as migrantes bolivianos/as. Frente a esa posibilidad, algunos/as vendieron la tierra, abandonando la producción y dedicándose a otros trabajos. En algunas ocasiones, como asalariados/as en labores relativamente bien pagas o en mejores condiciones que la horticultura; en otras, emprendiendo nuevas actividades de comercialización, como la venta de verdura en el mercado o en verdulerías u otros comercios propios. Y otros/as (presumiblemente la mayoría) mantuvieron la tierra pero ya no la trabajaron (García y Kebat, 2008). Por diferentes motivos, aunque muchos de ellos/ as por falta de descendientes que quisieran seguir en la producción, decidieron arrendar las hectáreas que poseían y pasaron de productores/as a rentistas o a gestionarlas con medieros/as (Lemmi, 2015b).

El alejamiento definitivo de la producción -si no ocurrió en la etapa crítica de fines de los 90- se fue concretando en la medida en que estas familias llegaron a la etapa de reemplazo y en ausencia de descendencia que efectivizara el recambio generacional. Las nuevas generaciones no estuvieron dispuestas a trabajar en una actividad que no podía garantizar los niveles de consumo alcanzados por sus familias, luego de décadas de procesos de trabajo, ahorro e inversión. Muchos/as crecieron viendo cómo el trabajo de sus padres y madres no era recompensado en la coyuntura crítica de la década del 90. Además, avanzaron en sus niveles de escolarización formal y buscaron empleos, oficios, profesiones que les pudieran garantizar seguridad y regularidad en el ingreso, la posibilidad de trabajar horas acotadas y contar con períodos de vacaciones, con lo que se consolidaba la tendencia hacia una movilidad social ascendente respecto de las posiciones sociales de sus antecesores/as, los/as primeros/as inmigrantes. ${ }^{8}$

La crisis de fines de la década del 90 , como toda crisis, funcionó como disciplinadora en varios sentidos. Por un lado, en un sentido productivo ya que aquellos sectores menos competitivos tendieron a la desaparición: los/as productores/as dejaron de trabajar las tierras pero no se deshicieron de ellas. A su vez, algunos/as medieros/as y trabajadores/as asalariados/as pasaron a formar parte del ejército de desocupados/as en busca de subsidios estatales para vivir. Por otro lado, la crisis también fue disciplinadora en un sentido subjetivo, ya que la salida de la producción de los/as productores/as dejó temerosos/as a los/as que sobrevivieron, lo que generó reticencias a futuras inversiones. Para muchos/as de los/as productores/as, descendientes de la primera oleada de inmigrantes, fue la pérdida de una trayectoria histórica en el sector que se remontaba a padres, madres y abuelos/as (Lemmi, 2015a, 2015b). El comienzo de la recesión en 1998, que culminó en la crisis del 2001, dio por resultado en el territorio periurbano platense la desaparición de un $40 \%$ de la superficie hortícola, mientras que cesaron en su actividad o desaparecieron más de 100 explotaciones hortícolas, con una disminución de 20.000 toneladas en la producción y con un $24 \%$ de los/as trabajadores/ as desocupados/as de la actividad (García y Kebat, 2008). 


\section{Trayectorias migrantes LATINOAMERICANAS: DE ESCALERA GRINGA A BOLIVIANA}

Ahora bien, desde mediados de los 90 ha ido ocurriendo un reemplazo de las familias que se hacen cargo de producir hortalizas: mientras las trayectorias de los/as migrantes/as europeos/as y su descendencia afrontaron, en diferente grado, problemas de continuidad, comenzaron a aparecer nuevas trayectorias y reposicionamientos de nuevos/as productores/as desde su inserción previa como medieros/as. Empezaron como peones/as de los/as productores/as europeos/as y sus descendientes y se fueron consolidando de a poco junto al trabajo de toda su familia como peones/as y medieros/as. Tal como medio siglo antes habían llegado los/as migrantes italianos/as, los/as migrantes bolivianos/as arribaron al trabajo acompañados/as de todo el núcleo familiar. Si bien en un contexto diferente, muchos/as lograron emprender su camino de ascenso social, subiendo los peldaños de la escalera construida por los/as pioneros/as europeos/as.

Los/as migrantes bolivianos/as que habían llegado como peones/as, para luego ser medieros/as y, sobre todo post-crisis del 2001, productores/as con base en el arriendo de tierras, no pudieron aún alcanzar el peldaño de la posesión de estas. Si bien para los/as horticultores/as que llegaron al país promediando los años 40 el acceso a la tierra fue relativamente posible, no lo es para los/as migrantes recientes. Las inversiones en la tecnología para la producción que requiere una quinta son muy costosas, y debe disponerse de una importante suma de capital para comprar invernáculos, instalar riego, comprar o alquilar el tractor, etc.; $\mathrm{y}$, en el caso de los/as que comercializan su propia verdura, de vehículos para llegar hasta el mercado. Esto lleva a que no puedan disponer de un excedente suficiente para invertir en la compra de tierras, lo que implicaría además inmovilizar importantes sumas de capital. De manera asociada, debemos adicionar la especulación inmobiliaria que lleva los precios de la tierra a niveles altísimos, muchas veces inaccesibles para los/as arrendatarios/as (García, 2014; García y Le Gall, 2009; Waisman, 2012; Castro, 2016; Merchán, 2016).

El acceso al factor tierra representa una marcada diferencia en las condiciones de producción de "viejos/ as" y "nuevos/as" quinteros/as. Por otra parte, estas diferencias se prolongan en notables contrastes en las condiciones de vida. En este contexto de arriendo generalizado, la posibilidad de construir viviendas de material no aparece como un horizonte de inversión plausible, ya que quedarían en propiedad del/la dueño/ a de la tierra una vez terminado el contrato. Por esto, las viviendas de los/as migrantes bolivianos/as (sean estos/as productores/as, peones/as o medieros/as) son muy precarias, construidas con maderas y chapas, en formato de casillas desmontables con poca iluminación y ventilación, sin los servicios básicos para vivir (baño, agua potable) y con instalaciones deficientes de gas, luz y calefacción. A su vez, esto tiene consecuencias sobre el consumo: tienden a invertir su dinero directamente en la producción o eventualmente en bienes muebles como vehículos (Attademo, 2009; Pineda, 2011; Cieza, 2012; Lemmi, 2015a).

El reemplazo operado en el tejido social hortícola platense ha sido posible porque estos/as sujetos/as que provienen de orígenes muy pobres y en situaciones precarias por su condición de migrante irregular están dispuestos/as a ponerle el cuerpo a una actividad trabajo-intensiva, con condiciones laborales muy duras, sumamente inestable y en la que nunca se pueden predecir las ganancias que se obtendrán, y aceptando retornos menores por los recursos que ponen en juego en la producción. Los niveles de consumo aceptable para estos/as sujetos/as son otros, y más allá de la búsqueda de renta, están dispuestos/as a adecuarse a la situación existente que, muchas veces, sólo representa la reproducción de las necesidades familiares y de las condiciones de producción, soportando irregularidades en los niveles de acumulación derivadas de la impredecibilidad del lucro (Waisman, 2014; Castro, 2016). 


\section{NuEVOS DESAFÍOS EN LA CONTINUIDAD INTERGENERACIONAL DEL OFICIO}

Y como la historia parece más bien cíclica, empiezan a reiterarse en este mecanismo de movilidad social ascendente típico de la horticultura -la escalera- elementos que ponen en cuestión el reemplazo intergeneracional del oficio, ahora para los/as productores/as de origen boliviano.

Esto puede ser explicado en función de varias dimensiones que inciden en la dirección y continuidad de estas trayectorias socioproductivas. Algunas de ellas se vinculan a la dinámica familiar: junto con la movilidad social ascendente aparecen nuevas expectativas de consumo y acceso a mejores credenciales educativas. Obviamente, sabemos que esta no es la realidad de todas las familias involucradas en la actividad, ya que la estructura social segmentada étnico-nacionalmente -con amplia mayoría de bolivianos/as y sus descendientes- está atravesada por relaciones de desigualdad: hay patrones con diferentes niveles de capitalización y trabajadores/as (en su mayoría medieros/as) (Waisman, 2011b; Lemmi, Morzilli y Moretto, 2018).

Otras variables de orden estructural ponen en cuestión también la continuidad de estas trayectorias: un modelo productivo costoso que supone gran inestabilidad y numerosos riesgos (crisis periódicas de sobreproducción; riesgos climáticos y de plagas, durante la comercialización); una actividad trabajo-intensiva con niveles de acumulación sumamente variables en función de los ciclos productivos; coyunturas históricas que desalientan la migración en períodos acotados (cambio de orientación política de la coalición gobernante en Bolivia), en tanto el Estado Plurinacional de Bolivia aparece como un lugar con oportunidades para vivir e incluso para retornar (Waisman y Rispoli, 2015; Féliz, López y García, 2016).

Por otra parte, debemos considerar variables coyunturales que refuerzan obstáculos en el equilibrio inestable de estas trayectorias: nuevas inclemencias climáticas y el cambio de orientación estatal en materia de política económica y políticas públicas, en el marco del recambio en la coalición gobernante -a nivel nacional, provincial y local- con la asunción de la Alianza Cambiemos (2015-2019).

En función de las medidas implementadas se producen cambios en el contexto macroeconómico: una devaluación del peso de más del $50 \%$, que redundó en un incremento de la inflación de más del $40 \%$ en el primer año de gobierno (Fernández y Lemmi, 2017). Este proceso inflacionario trajo aparejado una retracción del consumo interno -que repercutió especialmente en el rubro alimentos- y en el valor de los alquileres que pagan los/as productores/as. También resultan especialmente relevantes para el sector las quitas de subsidios a los servicios de gas, electricidad y agua, que traen como consecuencia la suba de tarifas. El caso de la electricidad es de central importancia en función de su uso productivo (en el sistema de riego), además de su uso doméstico. Por su parte, el aumento del gas, si bien no incidió de manera directa -debido a que el territorio periurbano productivo no se encuentra integrado a la red de gas-, sí lo hizo de manera indirecta debido al aumento del valor de la garrafa (Fernández y Lemmi, 2017).

Por otra parte, coyunturas climáticas como la tormenta del 5 de febrero de $2017^{9}$ visibilizan la situación de precariedad estructural que atraviesa a gran parte de los/as productores/as hortícolas. La recesión económica y las inclemencias climáticas representan un fuerte obstáculo para la reproducción de los/as pequeños/as productores/as, tanto hacia fines de los 90 como en la coyuntura más reciente (2015-2019): problemas en el acceso a los recursos productivos (insumos importados, tenencia de la tierra en contexto reciente), en la apropiación de las ganancias durante la etapa de comercialización, en el acceso a asesoramiento técnico, entre otros.

Sin embargo, existe una importante diferencia en la posición estructural de los/as productores/as que lideraban el proceso productivo hasta la década de 1990 y los/as productores/as actuales: la tenencia de la tierra. De este modo, ante la crisis de fines del siglo pasado, los/as descendientes de la migración europea -al ser dueños/as de la tierra- pudieron volver a insertarse en el circuito como oferentes de tierras para arrendar, cuando no volver ellos/as mismos/as como productores/as. En cambio, en el caso de los/as migrantes recientes, la nueva coyuntura crítica impuso importantes desafíos en la continuidad de sus trayectorias en 
el sector, con dificultades de recapitalización ante la inclemencia climática, para recomenzar un nuevo ciclo productivo.

Una vez más -trazando otro paralelismo con la crisis de los años 90-, la acción colectiva y la lucha de los/ as quinteros/as irrumpe en la arena pública para reclamar por ayuda estatal para esta actividad económica. Sin embargo, debemos tener presente que las transformaciones en la estructura social hortícola han tenido también su correlato en la estructura de representaciones del sector. La APHLP -protagonista de la lucha durante la década del 90- ha perdido capacidad para canalizar las demandas de las bases, como consecuencia del recambio étnico-nacional que ha sufrido la categoría de productor/a (Lemmi y Waisman, 2013; Lemmi, 2019). Sin embargo, en este nuevo contexto se han multiplicado las organizaciones en el sector, ${ }^{10}$ con más de veinte organizaciones nucleadas en la Mesa Regional de Pequeños Productores Agropecuarios de La Plata ${ }^{11}$ (Ferraris y Bravo, 2014; Bártola, 2017). Durante los últimos años han llevado a cabo diversas protestas tractorazo, paro quintero, verdurazos, cortes y movilizaciones-, ${ }^{12}$ a fin de visibilizar la coyuntura desfavorable de la actividad y reclamar medidas apropiadas para el sector. ${ }^{13}$

Las asociaciones y los movimientos de productores/as surgidos en la última década poseen rasgos diferentes de los que motorizaron la lucha en los años 90. En este sentido, todas las organizaciones, en la actualidad, además de las reivindicaciones propia de la producción, acompañan su lucha con actividades referidas al género, la juventud, la educación y el ambiente, así como reivindican el origen étnico/nacional y las raíces culturales de sus asociados/as, mayoritariamente de origen boliviano. Casi la totalidad de las asociaciones y movimientos poseen sus espacios/áreas de género, y en ese marco desarrollan actividades pensadas específicamente para las mujeres. Allí, las productoras se encuentran y debaten las situaciones particulares que atraviesan como mujeres en el espacio hortícola. Asimismo, realizan actividades de empoderamiento y construyen la red feminista necesaria para acompañarse en los avatares cotidianos de la vida (Insaurralde, Lemmi, Lemmi, Remorino y Velazco, 2019; Insaurralde y Lemmi, 2020; Moretto, Nieto y Torres, 2018).

Lo mismo sucede con los espacios orientados a los/as jóvenes que forman parte de las familias productoras, que no sólo acompañan a los/as adultos/as en las tareas productivas, sino que se ven atravesados/as por problemáticas propias de ese momento de la vida. Los/as jóvenes realizan fuertes esfuerzos para construir trayectorias educativas exitosas, de manera de obtener las credenciales que les permitirán en un futuro conseguir mejores trabajos (Lemmi, Morzilli y Castro, 2020).

De igual manera, se duplican en las asociaciones las áreas de agroecología, en las que las familias productoras aprenden los métodos de producción agroecológica, así como comienzan a dedicar parte de sus tierras a producir bajo estas formas. ${ }^{14}$

Tal como una de las autoras lo ha analizado en otro trabajo, si bien los problemas estructurales no desaparecen en ningún momento, la acción colectiva no siempre está presente (Fernández y Lemmi, 2017). De hecho, durante los dos períodos de administración kirchnerista (2003-2015) el conflicto aparece solapado. De acuerdo con lo analizado en dicho trabajo, esto puede ser explicado por las medidas macroeconómicas que sostuvieron el consumo interno y la implementación de políticas públicas orientadas a la contención y acompañamiento de los/as horticultores/as.

En este contexto crítico que estamos describiendo (2016-2019) -cambio de orientación en la política estatal y coyunturas climáticas-, la conflictividad reaparece (Fernández y Lemmi, 2017). Siguiendo el planteo de estos/as autores/as, se presentan algunos ejes comunes con el proceso de lucha desarrollado durante la década de 1990: el inicio de la protesta en momentos de crisis de rentabilidad; la modalidad adoptada (movilizaciones, cortes de ruta, tractorazos, declaraciones públicas); el pedido de subsidios en un contexto de reducción del gasto público; la solicitud de que se declare la Emergencia Agropecuaria; el reclamo por la reglamentación de la comercialización; el pedido de créditos blandos. Pero también se encuentran diferencias en los reclamos de ambos períodos: el reclamo masivo por el acceso a la tierra y al crédito, y la mejora en las condiciones de vida (Fernández y Lemmi, 2017, p. 279). Estos son los tres factores estructurales que se 
agravaron en la reconfiguración de la estructura hortícola, con su segmentación étnico/nacional y la masiva presencia de sujetos/as de origen boliviano y su descendencia.

Para cerrar, queremos dejar planteado que estos problemas estructurales representan un serio desafío a la continuidad de las trayectorias socioproductivas de numerosas familias insertas en el sector. Se trata, además, de las familias productoras que le ponen el cuerpo a la producción de alimento que abastece a la región más poblada del país, la Región Metropolitana de Buenos Aires (RMBA), con trece millones de habitantes.

\section{REFLEXIONES FINALES}

La movilidad social ascendente y el recambio étnico/nacional son dos aspectos centrales en las transformaciones del tejido social hortícola platense, en directa relación con cambios en la principal actividad económica y con factores coyunturales, que actuaron condicionando las trayectorias socio-productivas de quinteros/as insertos/as en la actividad.

El análisis de estas trayectorias nos permite realizar una serie de señalamientos críticos respecto de las investigaciones precedentes. En primer lugar, hemos relevado en las entrevistas a los/as migrantes ultramarinos/as y sus descendientes procesos similares de ascenso social a los vivenciados por los/as migrantes bolivianos/a. Esto nos permite ampliar la caracterización de la escalera como mecanismo tradicional de movilidad en el sector, que reconoce una mayor profundidad temporal y que no se restringe a una categoría de adscripción étnico/nacional.

A su vez, las particularidades de las condiciones laborales y de las trayectorias educativas de los/as hijos/ as de los/as productores/as bolivianos/as abren un interrogante sobre la continuidad de algunas de las trayectorias socio-productivas vigentes, cuestionando la escalera en otro sentido: ¿el último peldaño es ser productor/a? Es un trabajo duro, mal recompensado, que pareciera haber sido aceptado históricamente por sujetos/as migrantes con antecedentes familiares en actividades productivas y condiciones de vida que los/as llevan a considerar aceptables los réditos obtenidos por trabajar en esta actividad. Pero tanto en el pasado con los/as migrantes europeos/as, como en la actualidad con los/as bolivianos/as, en el transcurso de un par de generaciones algunos/as logran el proceso de movilidad social ascendente y entonces la escalera se transforma en trampolín que los impulsa a nuevos horizontes y expectativas: estudiar, obtener títulos profesionales, buscar un trabajo menos comprometido desde lo corporal, con ganancias que se puedan predecir. Las condiciones duras y de equilibrio inestable de la actividad la transforman en fuertemente expulsiva, que es escogida por quienes no tienen otras opciones.

Por otra parte, el contexto de los últimos años de una nueva coyuntura crítica para la actividad (con paralelismos con la de fines de la década del 90) abre un interrogante sobre la continuidad de algunas trayectorias vigentes pero en el sentido opuesto de la movilidad social descendente (sobre todo, la de quinteros/as con menor nivel de capitalización). La situación de equilibrio inestable de muchos/as quinteros/as en una actividad atravesada por diversos riesgos permite imaginar que esta escalera puede ser transitada nuevamente en un sentido descendente, aunque ello es difícil de rastrear y cuantificar por razones metodológicas.

Finalmente, hemos analizado la conflictividad que atraviesa al sector, en dos momentos históricos en los que cobra especial visibilidad. Esto nos permitió marcar cambios y continuidades. Las diferencias señaladas -la aparición de nuevos temas de lucha: el acceso a la tierra, al crédito y la mejora en las condiciones de vidase encuentran en directa vinculación con las transformaciones en la estructura hortícola que explicamos (en la que juega un rol central la intensificación del modelo productivo). Sin embargo, más allá de estas importantes reconfiguraciones, queremos señalar que la conflictividad se torna más significativa en sus continuidades, ya que pone al descubierto los problemas estructurales del sector. Esto es, los altos costos de un planteo productivo basado en la adquisición de insumos industrializados importados y un esquema de comercialización en el que los/las productores/as participan de manera desigual, dada su inserción atomizada. 
Son estos factores los que imponen un fuerte desafío en la continuidad de las trayectorias socioproductivas de numerosas familias productoras. Creemos que es central visibilizar esta situación y señalar la relevancia de intervenir en el sector a partir de política pública específica, ya que se trata de acompañar -nada más ni nada menos- a los/las sujetos/as que producen alimento para la región más poblada del país. Ello, en definitiva, estaría problematizando importantes temas, como la seguridad y soberanía alimentaria.

\section{REFERENCIAS}

Attademo, S. (2009). Lazos sociales y estrategias: ¿una opción para las familias hortícolas empobrecidas? Mundo Agrario, 9(17). Recuperado de http://www.mundoagrario.unlp.edu.ar/article/view/v09n17a09

Bártola, D. E. (2017). Más allá de la supervivencia: La participación de pequeños productores del Cordón Horticola del Gran La Plata en asociaciones y cooperativas como estrategias para la reproducción social en el periodo 2010-2017 (Tesis de Licenciatura). FaHCE, UNLP. La Plata, Argentina. Recuperada de http://www.memoria.fahce.unlp .edu.ar/tesis/te.1485/te.1485.pdf

Benencia, R. (1999). El concepto de movilidad social en los estudios rurales. En N. Giarraca (Coord.), Estudios Rurales. Teorias, problemas y estrategias metodológicas (pp. 77-92). Buenos Aires: La Colmena.

Benencia, R., Quaranta, G. y Souza Casadinho, J. (Coords.) (2009). Cinturón Hortícola de la Ciudad de Buenos Aires. Cambios sociales y productivos. Bs. As.: CICCUS.

Blanco, M. y Pacheco, E. (2003). Trabajo y familia desde el enfoque del curso de vida: dos subcohortes de mujeres mexicanas. Papeles de población, 9(38), 159-193. Recuperado de http://www.scielo.org.mx/scielo.php?script=s ci_arttext\&pid=S1405-74252003000400006

Bourdieu, P. (1997). Razones prácticas. Sobre la teoría de la acción. Barcelona: Anagrama.

Castillo, V., Novick, M., Rojo, S. y Yoguel, G. (2005). Trayectorias laborales y rotación del empleo: restricciones para el desarrollo de competencias técnicas. Ponencia presentada en el $7 \mathrm{mo}$ Congreso de especialistas en estudios del trabajo "Nuevos escenarios en el mundo del trabajo: rupturas y continuidades". Bs. As., 10 al 12 de agosto.

Castro, A. (2016). Saberes migrantes. Trayectorias de productores bolivianos del periurbano platense (Tesis de Licenciatura). FaHCE, UNLP. La Plata, Argentina. Recuperada de http://www.memoria.fahce.unlp.edu.ar/tr ab_eventos/ev.10723/ev.10723.pdf

Cieza, G. (2012). La problemática del agua en quintas del Cinturón Hortícola Platense. Boletín Hortícola de la Facultad de Ciencias Agrarias y Forestales, 17(49).

Dávolos, P. (2001). Después de la privatización: trayectorias laborales de trabajadores con retiro voluntario. Revista Estudios del Trabajo, 21, 69-95. Recuperado de http://www.aset.org.ar/revista.php?rid=16

Elder, G. (1991). Family transitions, cycles, and social change. En P. A. Cowan y E. M. Hetherington (Eds.), Family transitions (pp. 31-55). New Jersey: Lawrence Erlbaum Associates.

Elder, G. (1994). Time, Human Agency, and Social Change: Perspectives on the Life Course. Social Psychology Quarterly, 57(1), 4-15.

Féliz, M., López, E. y García, M. (Coords.) (2016). Desarmando el modelo: Desarrollo, conflicto y cambio social tras una década de neodesarrollismo. Buenos Aires: El Colectivo.

Fernández, L. y Lemmi, S. (2017). Nuevos sujetos, viejos reclamos. Conflictos en la horticultura platense ayer y hoy. Revista Estudos Sociedade e Agricultura, 25(1). Recuperado de https://revistaesa.com/ojs/index.php/esa/articl e/view/1153/564

Ferraris, G. y Bravo, M. L. (2014). Organizaciones de productores hortícolas del Cinturón Verde de La Plata. Trabajo presentado en las VIII Jornadas de Sociología de la UNLP. Recuperado de http://jornadassociologia.fahce.unlp .edu.ar/viii-jornadas/vii-jornadas-2012/search?Subject\%3Alist=2014Mesa26

Frassa, M. J. (2005). El mundo del trabajo en cambio. Trayectorias laborales y valoraciones subjetivas del trabajo en un estudio de caso. Ponencia presentada en el 7 mo Congreso de especialistas en estudios del trabajo "Nuevos escenarios en el mundo del trabajo: rupturas y continuidades". Buenos Aires, del 10 al 12 de agosto. 
Garat, J.J., Selis, D. y Velarde, I. (1999). La ocupación y transformación del espacio rural en el Partido de La Plata. Ponencia presentada en las I Jornadas de Estudios Agrarios y Agroindustriales. Buenos Aires, noviembre.

García, M. (2011). El Cinturón Hortícola Platense: ahogándonos en un mar de plásticos. Un ensayo acerca de la tecnología, el ambiente y la política. Revista Theomai, 23. Recuperado de http://revista-theomai.unq.edu.ar/N UMERO\%2023/contenido_23.htm

García, M. (2014). "Fuerza de trabajo en la horticultura de La Plata (Buenos Aires, Argentina): Razones y consecuencias de su competitividad". Trabajo y Sociedad, 22, 67-85. Recuperado de http://www.scielo.org.ar/s cielo.php?script=sci_arttext\&pid=S1514-68712014000100004

García, M. y Hang, G. (2007). Difusión-adopción tecnológica en el cinturón hortícola platense. Ponencia presentada en el $30^{\circ}$ Congreso Argentino de Horticultura y $1^{\circ}$ Simposio Internacional sobre Cultivos Protegidos de ASAHO. La Plata, del 25 al 28 de septiembre.

García, M. y Kebat, C. (2008). Transformaciones en la horticultura platense. Una mirada a través de los censos. Revista Realidad Económica, 237. Recuperado de http://www.iade.org.ar/articulos/transformaciones-en-la-horticultur a-platense-una-mirada-traves-de-los-censos

García, M. y Le Gall, J. (2009). Reestructuraciones en la horticultura del AMBA: tiempos de boliviano. Ponencia presentada en el IV Congreso Argentino y Latinoamericano de Antropología Rural. Mar del Plata, del 25 al 27 de marzo.

García, M. y Lemmi, S. (2011). Territorios pensados, territorios migrados. Una historia de la formación del territorio hortícola platense. Párrafos Geográficos, 10(1), Recuperado de http://igeopat.org/parrafosgeograficos/index.ph p?option $=$ com_content\&view $=$ category\&id $=10$

Graffigna, M. L. (2005). Trayectorias y estrategias ocupacionales en contextos de pobreza: una tipología a partir de los casos. Trabajo y Sociedad, VI(7). Recuperado de http://www.redalyc.org/pdf/3873/387334679005.pdf

Gutman, G., Gutman, P. y Dascal, G. (1987). El campo en la ciudad. La producción agrícola en el Gran Buenos Aires. Buenos Aires: Centro de Estudios Urbanos y Regionales (CEUR).

Hang, G., Bifaretti, R. y Sarandón, R. (1995). Caracterización del sistema de producción hortícola empresarial en el Partido de La Plata, Argentina. Revista de la Facultad de Agronomía de La Plata, 71.

Insaurralde Martínez, N., Lemmi González, L., Lemmi González, S., Remorino Friga, N. y Velazco Barbiero, R. R. (2019). Feminismos en ronda. Diálogos para mirarnos hacia adentro de la piel. Buenos Aires: El Bosque. Recuperado de https://editorialbosque.wordpress.com/2019/03/06/trabajos-realizados/

Insaurralde, N. y Lemmi, S. (2020). Cuerpos Productivos, cuerpos reproductivos. El caso de las mujeres productoras de hortalizas del Gran La Plata (2017). En F. González Maraschio y F. Villarreal (Comps.), La agricultura familiar entre lo rural y lo urbano (pp. 107-130). Buenos Aires: EdUNLu.

Lemmi, S. (2009). Izquierda y cuestión agraria. El caso del Partido Comunista Revolucionario y La Asociación de Medieros y Afines. Ponencia presentada en VI Jornadas de Investigación y Debate "Territorio, poder e identidad en el agro argentino". Instituto de Investigaciones Geohistóricas, CONICET, Universidad Nacional del Nordeste. Chaco. Mayo.

Lemmi, S. (2015a). La dialéctica entre conciencia y existencia. Condiciones de vida, conflicto y conciencia de clase en los horticultores del Gran La Plata (Prov. de Buenos Aires, Argentina), 1940-2003. Revista Izquierdas, 25, 228-257. Recuperado de http://www.izquierdas.cl/96-2015/103-numero-25-octubre

Lemmi, S. (2015b). Conflicto y organización en la horticultura del Gran la Plata (Prov. de Buenos Aires, Argentina), 1994-2002. Revista Interdisciplinaria de Estudios Agrarios, 43, 27-54. Recuperado de http://www.ciea.com.ar/r evista-interdisciplinaria-de-estudios-agrarios/revista-num-43/

Lemmi, S. (2019). Productor/a Hortícola (Prov. de Buenos Aires, Arg. 1940- 2019). En A. Salomón y J. Muzlera (Eds.), Diccionario del Agro Iberoamericano (pp. 467-476). Bs. As.: Teseo Ediciones. Recuperado de https://w ww.teseopress.com/diccionarioagro/

Lemmi, S., Morzilli, M. y Castro A. (2020). Jóvenes que horticultean, adultos/as horticultores/as. Aproximaciones al sentido de juventud en familias migrantes bolivianas que se dedican a la horticultura en el Gran La Plata (prov. 
de Buenos Aires, Argentina). Millcayac 7(13). Recuperado de http://revistas.uncu.edu.ar/ojs/index.php/millc a-digital/article/view/3544

Lemmi, S., Morzilli, M. y Moretto, O. (2018). Para no trabajar de sol a sol. Los sentidos de la educación en jóvenes y adultos/as integrantes de familias migrantes bolivianas hortícolas del Gran La Plata-Bs. As., Argentina. RUNA, 39(2). Recuperado de http://revistascientificas.filo.uba.ar/index.php/runa/article/view/5188/4961

Lemmi, S. y Waisman, M. A. (2013). “... a nuestros hijos, posibles futuros horticultores, una tierra bien labrada y sin espinas...". La trayectoria de la Asociación de Productores Horticolas de La Plata (1983-2011). Ponencia presentada en XIV Jornadas Interescuelas / Departamentos de Historia. Universidad Nacional de Cuyo. Mendoza, del 2 al 5 de octubre.

Merchán, A. G. (2016). Valorización de la tierra en el Cinturón Horticola Platense. Disparidad en el valor de los arrendamientos (Tesis de Maestría). FCAyF, UNLP. La Plata, Argentina. Recuperada de http://sedici.unlp.ed u.ar/handle/10915/53577

Moretto, O., Nieto, M. E. y Torres, M. A. (2018). Tejiendo resistencias: las organizaciones de mujeres y el abordaje de la violencia ante la ausencia del Estado en los territorios. Ponencia presentada en V Jornadas CInIG de Estudios de Género y Feminismos y III Congreso Internacional de Identidades. La Plata.

Muñiz Terra, L. (2005). El aporte del concepto de trayectoria laboral para el estudio de las vivencias de los ex trabajadores de YPF: reflexiones a partir de la práctica. Ponencia presentada en el $7 \mathrm{mo}$ Congreso de especialistas en estudios del trabajo: "Nuevos escenarios en el mundo del trabajo: rupturas y continuidades". Buenos Aires, del 10 al 12 de agosto.

Pineda, C. (2011). Vivienda Desarmable. Experiencia constructivista en 6, 7, 8 actos. Boletín Hortícola de la Facultad de Ciencias Agrarias y Forestales, 16(47).

Ringuelet, R. (Comp.) (2000). Espacio tecnológico, población y reproducción social en el sector hortícola de La Plata. Estudios e Investigaciones, 39. La Plata: UNLP-FAHCE. Recuperado de http://www.memoria.fahce.unlp.edu. ar/libros/pm.182/pm.182.pdf

Ringuelet, R., Attademo, S., Archenti, A. y Salva, M. C. (1991). Cuestiones agrarias regionales. Estudios e Investigaciones, 6. La Plata: UNLP-FAHCE. Recuperado de http://www.memoria.fahce.unlp.edu.ar/libros/pm $.84 / \mathrm{pm} .84 . \mathrm{pdf}$

Vega, M. (1999). Integración vertical y productos diferenciados. Boletín Hortícola de la Facultad de Ciencias Agrarias y Forestales, 7(23), 33-35.

Waisman, M. A. (2011a). Superando dualismos: trayectorias socio-productivas en el abordaje de las transformaciones en la estructura social hortícola platense. Mundo Agrario, 12(23). Recuperado de http://www.mundoagrario.u nlp.edu.ar/article/view/v12n23a15

Waisman, M. A. (2011b). Trayectorias socio-productivas en el cordón horticola platense: desafios en la continuidad intergeneracional del oficio. Ponencia presentada en las Terceras jornadas de antropología social del centro Olavarría "Redefiniciones y continuidades: debates desde la antropología", Universidad Nacional del Centro de la Provincia de Buenos Aires. Olavarría, 30 de septiembre, 1 y 2 de octubre.

Waisman, M. A. (2012). "Dime a quién le vendes y te diré quién eres...". Relaciones entre actores relevantes y dinámica histórica en la comercialización de hortalizas en el periurbano de la ciudad de La Plata. Ponencia presentada en las Jornadas Académicas Tierra y Movimientos Sociales en la Argentina. "A cien años del Grito de Alcorta". Universidad Nacional de Rosario, Facultad de Humanidades y Artes. Rosario, 29, 30 y 31 de agosto.

Waisman, M. A. (2014). La intensificación del modelo productivo horticola y sus implicancias en la dinámica territorial periurbana platense. Ponencia presentada en el XI Congreso Argentino de Antropología Social Facultad de Humanidades y Artes "Perspectivas críticas en Antropología Social. Construcciones teóricas y prácticas desde América Latina". Rosario, 23 al 26 de julio.

Waisman, M. A. y Rispoli, F. (2015). Principios de diferenciación y distinción entre horticultores bolivianos en el periurbano platense. Ponencia presentada en las V Jornadas de Antropología Social del Centro "Antropología social y mundos posibles en transformación". Olavarría, 30 de septiembre, 1 y 2 de octubre. 


\section{Notas}

1 Lemmi, Soledad (2014), "Vivir como peón, pensar como patrón". Conflicto, organización política y conciencia de clase en el sector hortícola del Gran La Plata (1953-2009). Tesis doctoral. Doctorado en Ciencias Sociales. Universidad Nacional de Quilmes. Waisman, Ma. Alejandra, Trayectorias socio-productivas en el proceso de reconfiguración del espacio social periurbano platense (tesis doctoral en proceso de redacción).

2 Es la categoría nativa con la que significan la pertenencia profesional. Su historia remite a que en la Argentina se reservó el término "huerta" para la actividad familiar y se empleó la expresión "quinta” para la actividad comercial. Ambas, a la vez, se distinguieron de la chacra, americanismo de "granja”. Las chacras se ubicaron en áreas claramente rurales y se dedicaron, además, a la ganadería menor y mayor en pequeña escala.

3 Fuente: Acervo testimonial.

4 En la mayoría de los casos aquí estudiados la mediería toma la forma de una relación contractual en la que el/la productor/ a dueño/a de la tierra aporta, además de dicho bien, los insumos para la producción, mientras que el/la mediero/a aporta únicamente su fuerza de trabajo y la de su familia. Lo recaudado por la venta de lo producido se reparte en porcentajes desiguales (70-30; 80-20, generalmente) entre ambos/as miembros/as de la relación. Existen, en menor medida, relaciones en las cuales el/la mediero/a aporta, además de su mano de obra, un pequeño porcentaje de los costos de los insumos, cambiando el porcentaje de lo recibido en carácter de ganancia. Sin embargo, esta última forma de relación es poco frecuente pues los/as sujetos/as que trabajan bajo relación de mediería suelen llegar a la producción sin ningún ahorro o dinero para invertir.

5 Fuente: Acervo testimonial.

6 Fuente: Acervo testimonial.

7 Acervo testimonial.

8 Cabe aclarar que la ciudad de La Plata es asiento no sólo de la Universidad que lleva su nombre sino también de la burocracia estatal provincial. Esto favoreció la posibilidad de que las jóvenes generaciones pudieran acceder a estudios universitarios de manera relativamente fácil o conseguir trabajos vinculados al Estado provincial.

9 Ver http://www.eldia.com/la-ciudad/los-horticultores-exigen-respuestas-200072, http://www.eldia.com/nota/20172-16-productores-platenses-claman-por-un-salvavidas-para-el-cordon-verde

10 Cabe mencionar que la multiplicación de organizaciones se vincula a las políticas públicas y de desarrollo rural implementadas durante los gobiernos kirchneristas, las que incentivaron el trabajo asociativo como metodología de intervención. Nos referimos a la institucionalización de la agricultura familiar como sujeto de políticas públicas y a la implementación de programas como Cambio Rural Bonaerense (2002-2009), Cambio Rural, el Monotributo Social Agropecuario, el Registro Nacional de la Agricultura Familiar, entre otros (Fernández y Lemmi, 2017).

11 La Mesa Regional de Pequeños Productores Agropecuarios de La Plata se conformó como consecuencia de una tormenta que causó daños en las quintas hacia fines de 2012, momento en el que se reunieron las organizaciones con el fin de solicitar apoyo económico a las autoridades de los diversos niveles estatales.

12 Ver http://www.infoplatense.com.ar/nota/2016-3-30-productores-horticolas-realizaran-un-tractorazo-en-las-rutas-q ue-llegan-hasta-la-plata, http://www.infoblancosobrenegro.com/noticias/12746-productores-horticolas-acamparan-f rente-a-gobernacion-y-amenazan-con-un-desabastecimiento, http://infoblancosobrenegro.com/noticias/13159-prod uctores-horticolas-vuelven-a-protestar-en-ruta-36-y-avenida-520

13 Entre los principales reclamos figuran: subsidio al gasoil y tarifa social para la electricidad; precio mínimo sostén de la verdura para el productor y precio tope para la venta al consumidor; fondos de insumos; regulación de alquileres; línea de créditos blandos a tasa subsidiada para afrontar la emergencia, entre otros.

14 Acervo testimonial. 